\title{
Pediatric primary anaplastic ganglioglioma with malignant neuronal component
}

\author{
Mehmet Atalar \\ Department of Radiology, Cumhuriyet University School of Medicine, Sivas, Turkey. E-mail: mhatalar@gmail.com \\ Received: 20th March 2019, Accepted: 16th September 2019
}

\section{Dear Editor,}

I read with great attention the case report entitled 'Pediatric primary anaplastic ganglioglioma with malignant neuronal component' reported by Kaymak-Cihan et al. ${ }^{1}$ in your prestigious journal. Although the case report was well designed in a broad sense, I still would like to emphasize several points I consider important regarding the radiological descriptions made throughout the manuscript. MRI descriptions under the header 'Figure 1' contain some errors. The MRI image described in Figure 1 belongs to a T1-weighted inversion recovery (IR) sequence but its legend states that it is a T1-weighted image. The post-contrast T1-weighted MR image given in Figure $1 \mathrm{~B}$ and described as depicting gadolinium enhancement belongs to postoperative MRI control examinations but not the preoperative period. The described lesion did not show contrast enhancement in the preoperative MRI examination.

Radiological descriptions being made by non-radiologists in manuscripts containing radiological images lead to misinformation of readers, thereby both reducing the impact factor of that article and call in question the prestige of the publishing journal. Hence, to avoid such inconveniences, it would be appropriate that radiological descriptions and assessments in published manuscripts be made by radiologists.

\section{REFERENCES}

1. Kaymak-Cihan M, Erdiş E, Bozkurt S, Ünver-Korğalı E. Pediatric primary anaplastic ganglioglioma with malignant neuronal component. Turk J Pediatr 2018; 60: 102-106.

\section{Reply}

\author{
Meriç Kaymak Cihan \\ Department of Pediatric Hematology and Oncology, Cumhuriyet University Faculty of Medicine, Sivas, Turkey.
}

\section{Dear Editor,}

We read the letter which was written to your journal regarding our case report "Pediatric primary anaplastic ganglioglioma with malignant neuronal component" 1 with great attention. The aim of the case presentation was to emphasize clinical evaluation (treatment and management of the patient), especially the pathological difference of the case by the presentation of malignant neuronal component of the tumor. For this reason, we think that the image in Figure 1A is sufficient for readers to be T1 weighted. In the MRI examination of
Figure 1B, the preoperative MRI of our case is mentioned in gadolinium retention.

In summary, we want to emphasize that radiological imaging was not at the forefront in our case and the case was evaluated mainly pathologically and in terms of treatment modalities.

\section{REFERENCES}

1. Kaymak-Cihan M, Erdiş E, Bozkurt S, Ünver-Korğalı E. Pediatric primary anaplastic ganglioglioma with malignant neuronal component. Turk J Pediatr 2018; 60: 102-106. 